DE

M E D I C I N A

T R O P I C A L

$\mathrm{DE}$

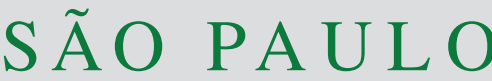

JOURNAL OF THE SÃO PAULO INSTITUTE OF TROPICAL MEDICINE

'Universidade de São Paulo, Instituto de Medicina Tropical, Laboratório de Micologia Médica, São Paulo, São Paulo, Brazil

2Universidade de São Paulo, Faculdade de Medicina, Hospital das Clínicas, Divisão de Clínica Dermatológica, Laboratório de Investigação Médica LIM 53, São Paulo, São Paulo, Brazil

${ }^{3}$ Universidade de São Paulo, Faculdade de Medicina, Departamento de Patologia, Laboratório da Disciplina de Patologia de Moléstias Transmissíveis, São Paulo, São Paulo, Brazil

${ }^{4}$ Faculdade de Medicina do ABC, Santo André, São Paulo, Brazil

Correspondence to: Maria Gloria Teixeira Sousa

Universidade de São Paulo, Instituto de Medicina Tropical, Laboratório de Micologia Médica, Av. Dr. Enéas de Carvalho Aguiar, 500, CEP 05403-000, São Paulo, SP, Brazil Tel: +55 1130617499 ,

Fax: +551130817190

E-mail: sousa.gloria@gmail.com

Received: 4 April 2019

Accepted: 21 August 2019

\section{In situ immune response in human dermatophytosis: possible role of Langerhans cells (CD1a+) as a risk factor for dermatophyte infection}

\author{
Ana Paula Carvalho Reis ${ }^{1,2}$, Franciele Fernandes Correia ${ }^{1,2}$, Thais Martins \\ Jesus $^{1,2}$, Carla Pagliari ${ }^{3}$, Neusa Y. Sakai-Valente ${ }^{2}$, Walter Belda Júnior ${ }^{2}$, Paulo \\ Ricardo Criado $^{4}$, Gil Benard ${ }^{1,2}$, Maria Gloria Teixeira Sousa ${ }^{(1,2}$
}

\section{ABSTRACT}

Dermatophytosis is a cutaneous mycosis caused by a plethora of keratinophilic fungi, but Trichophyton rubrum is the most common etiological agent. Despite its high prevalence worldwide, little is known about the host defense mechanisms in this infection, particularly the in situ immune response. Using an immunohistochemistry approach, we investigated the density of CD1a+, factor XIIIa+ and CD68+ cells in the skin of dermatophytosis patients. Langerhans cells (CD1a+ cells) were significantly decreased in the epidermis of patients, both in affected and unaffected areas. In the dermis, however, no differences in the density of macrophages (CD68+ cells) and dermal dendrocytes (factor XIIIa+ cells) were observed. These results suggest that the decreased number of Langerhans cells may be a risk factor for development of dermatophytosis.

KEYWORDS: Dermatophytosis. Innate immune response. Langerhans cells. Macrophages. CD68+. Factor XIIIa+. CD1a+. Trichophyton rubrum.

\title{
INTRODUCTION
}

Dermatophytosis is a superficial fungal infection with an outstanding morbidity rate in humans, affecting approximately $20 \%$ of the world population. More than 30 species of fungi, belonging to three main genera (Epidermophyton, Microsporum and Trichophyton), have been identified as causative agents ${ }^{1,2}$, but Trichophyton rubrum is the most frequent species in the human context, able to suppress and evade the host immune response, establishing infections refractory to current therapeutics ${ }^{3,4}$.

These fungi are characterized by invading the stratum corneum and other keratinized tissues like nail and hair, where they thrive by secreting enzymes and degrading keratin to obtain nutrients, also promoting tissue damage. Thus, clinical presentation is variable and relies on several factors as (i) the site of infection, (ii) the immunological response of the host, and (iii) the fungal species involved.

Overall, patients with acute superficial dermatophytosis mount cell-mediated immune responses against the causative agent, which is associated to resolution of the infection ${ }^{5,6-9}$. In contrast, those who suffer from chronic or recurrent infections are unable to develop this response ${ }^{10}$, but the reasons for this inability are not yet known. Recently, several reports described severe and occasionally life-threatening invasive disease (deep dermatophytosis) associated to genetic mutations in the innate immunity-associated molecule CARD $9^{6,8,11}$, highlighting the need to better understand the immune response in this infection. Recently, studies in animal 
models of dermatophytosis have demonstrated that Th17 and eventually Th1 immune responses were essential to the optimal control of this fungal infection ${ }^{12,13}$.

Immune cells like dendritic cells (DCs), macrophages, $\mathrm{CD}^{+}$and $\mathrm{CD} 8^{+} \mathrm{T}$ cells and natural killer (NK) cells, as well as some cytokines (i.e. interleukin [IL]-17, IL-1 $\beta$, and interferon [IFN]- $\gamma$ ) have been reported to mediate protection against different fungi in murine and human experimental systems $^{10,14}$. Particularly in the skin, macrophagesplay critical roles in initiation, maintenance and resolution of inflammation ${ }^{15}$, and DCs, the major antigen-presenting cells (APC), can clearly influence the development of cellular immunity to dermatophytes ${ }^{16}$.

Langerhans cells (LCs) are a population of DCs whose main function is antigen sampling and presentation in the epidermis $^{17}$. In the dermis, an equivalent DC population, called dermal dendrocytes (DD), are as potent as LCs in antigen presentation and they have been involved in the pathogenesis of different fungal infections as paracoccidioidomycosis and chromoblastomycosis ${ }^{18,19}$. Curiously, LCs recognize the antigen trichophytin ${ }^{20}$ and altered LC proliferation was associated to dermatophytosis ${ }^{21}$, hinting a possible role in this infection.

Considering the paucity of data about the host defense mechanisms in dermatophytosis, particularly in situ observations, the main objective of this study was the immunohistochemical analysis of LCs, DDs and CD68+ macrophages in skin lesions of dermatophytosis patients.

\section{MATERIALS AND METHODS}

\section{Patients}

Ten patients with dermatophytosis (involving at least three distinct body parts) were recruited at the Mycology Outpatient Clinic, Division of Clinical Dermatology, from the Hospital das Clinicas of the University of Sao Paulo. Skin samples from 10 healthy individuals undergoing plastic surgery were included as controls. Inclusion criteria were: (i) patients without any comorbidity affecting the immune response or predisposing to dermatophytosis (e.g., primary or secondary immunosuppression, diabetes mellitus, Cushing's disease, transplant recipients); (ii) subjects who had not used topical or systemic treatments one month prior to sample collection; (iii) isolation and identification of T. rubrum from skin lesions, performed by microscopic examination of lesion samples and culture in Agar Sabouraud (Becton, Dickinson and Company, Heidelberg, Germany) for fungal isolation. Patients who were under 18 years of age or pregnant were excluded.
The study was approved by the Ethics Committee of the Hospital das Clinicas of the University of Sao Paulo (Approval $\mathrm{N}^{\circ}$ 673/06) and all participants provided written informed consent prior to sample acquisition.

\section{Immunohistochemistry analysis}

One sample per patient, from the border of the active lesion, was taken with a standard dermatological biopsy puncher $(5 \mathrm{~mm})$. In the control group, skin samples were obtained from cosmetic surgery.

A streptavidin-biotin peroxidase method was used, as previously described ${ }^{22}$. Briefly, after deparaffinization and hydration, antigen recovery was performed in hot citrate bath $(10 \mathrm{~mm} / \mathrm{pH} 6.0)$ for $40 \mathrm{~min}$. Blockade of endogenous tissue peroxidase with $3 \%$ hydrogen peroxide solution was performed and samples were incubated overnight at $4{ }^{\circ} \mathrm{C}$ with the following primary antibodies: monoclonal mouse anti-human CD68 (clone KP1; Dako Corporation, Carpinteria, CA, USA); anti-CD1a (clone 010; Dako Corporation) or anti-factor XIIIa (clone E980; CM 357; Biocare Medical, Concord, CA, USA). Amplification and visualization of the reactions were performed with Novolink ${ }^{\mathrm{TM}}$ Max polymer detection systems (RE7260-K; Novocastra). Reactions were developed using a diaminobenzidine chromogen solution (DAB; Novocastra) and counterstained with Harris hematoxylin. All reactions were performed with positive and negative controls, the latter consisted in the omission of the primary antibody.

\section{Quantitative analysis of immunostained cells}

Immunostained cell counting was performed in an AxionVision microscope (Carl Zeiss, San Diego, CA, USA) coupled with Pentium IV and AxioShop 2 Plus software.

Cells were quantified in 10 fields featuring histological sections at $400 \times$ magnification and those stained in brown were considered immunoreactive.

\section{Statistical analysis}

The number of positive cells in the three groups was compared using Kruskal Wallis and Dunn's post-test with the level of significance set at $95 \%$. The Graph Pad Prism software, version 5.0 for Windows (Graph Pad software, San Diego, CA, USA) was used.

\section{RESULTS}

Our group of patients was composed of seven male (70\%) and three female (30\%) subjects, whose mean age 
was 38 years old (range 21-57). The patients presented either involvement of two (70\% of the cases) or one body segment $(30 \%)$. The anatomical sites affected were abdomen, buttocks, arms and thighs. The lesions were in general typical, circular or oval, and erythematous, often with scaling on the lesions, with more intense signals of inflammation within the limits of the lesions. Time of onset of the lesions ranged from 5 months to 2 years.

In the control group, six were male and four were female, their mean age was 34 years (range 28-52).

All samples from dermatophytosis patients were positive for T. rubrum. Histopathology analysis indicated perivascular lymphohistiocytic infiltration in the upper dermis and absence of neutrophils in the lesions (data not shown), albeit some authors described the presence of neutrophils in the stratum corneum, compact orthokeratosisand presence of hyphae in dermatophytic lesions ${ }^{23}$.

LCs are normally present in the epidermis and can be identified by the phenotypic marker CD1 $\mathrm{a}^{24}$. Albeit hematoxilin staining did not reveal any inflammatory infiltrate in the epidermis of patients (data not shown), the density of $\mathrm{CD} 1 \mathrm{a}^{+}$cells was significantly reduced in both, the area of affected $\left(90.7 \pm 64.3\right.$ cells $/ \mathrm{mm}^{2}$, mean \pm s.d. $)$ skin as well as the unaffected skin $\left(77.9 \pm 66.5\right.$ cells $/ \mathrm{mm}^{2}$, mean \pm s.d. $)$ compared to the control group $\left(158.5 \pm 99.2 \mathrm{cells} / \mathrm{mm}^{2}\right.$, mean \pm s.d.) (Figure 1A and Figure 2A).

For DDs, characterized by expression of Factor $\mathrm{XIIIa}^{25}$, no statistically significant differences were observed in their frequency between affected $\left(90.67 \pm 64.32\right.$ cells $/ \mathrm{mm}^{2}$, mean \pm s.d.) and unaffected skin dermis $\left(76.30 \pm 62.86\right.$ cells $/ \mathrm{mm}^{2}$, mean \pm s.d.) or when compared to the control group (118.9 \pm 49.93 cells $/ \mathrm{mm}^{2}$, mean \pm s.d.) (Figure $1 \mathrm{~B}$ and Figure $2 \mathrm{~B}$ ).

Finally, regarding dermal macrophages, the density of $\mathrm{CD}^{+} 8^{+}$cells in both groups (affected: $35.36 \pm 27.64$, unaffected: $50.18 \pm 35.33$ cells $/ \mathrm{mm}^{2}$ ) was also not statistically different and was similar to the one observed in the control group (38.91 \pm 26.85$)$ (Figure $1 \mathrm{C}$ and Figure 2C).
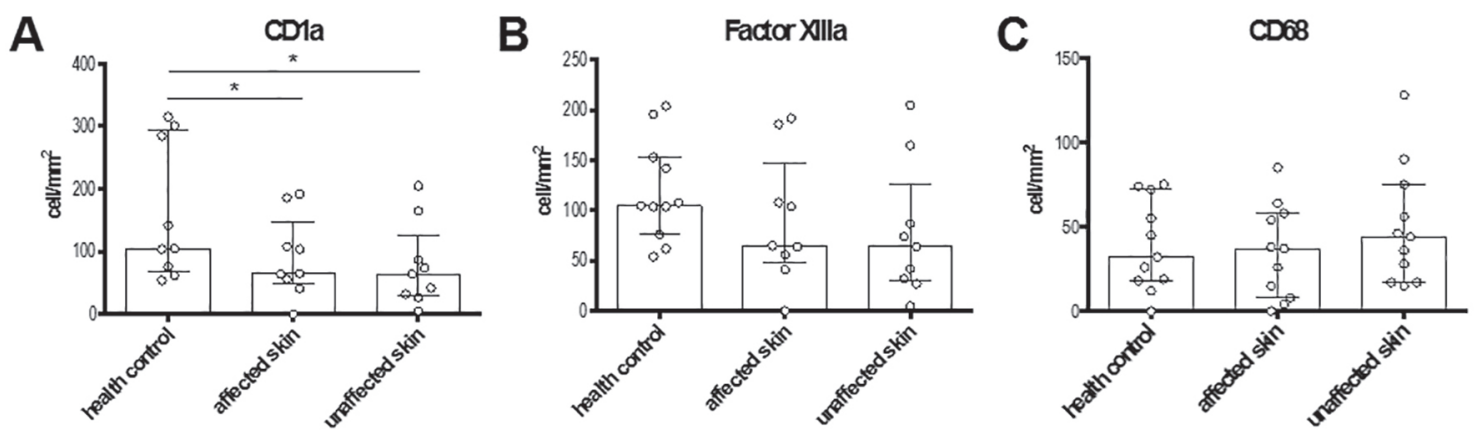

Figure 1 - Cell density of immunological markers at the lesion sites of patients with dermatophytosis. Dermatophytosis patients' skin samples (lesion areas and unaffected skin) and healthy controls skin samples were immunostained for the following cell populations: A) CD1a+ cells; B) Factor XIIla+ cells; C) $\mathrm{CD}^{+} 8^{+}$cells. Data are expressed as median \pm interquartile range of the density of immunostained cells. Statistical comparisons were performed with Kruskal Wallis and Dunn's post-test with a confidence level of $95 \% . \mathrm{n}=10 ;{ }^{*} p<0.05$.

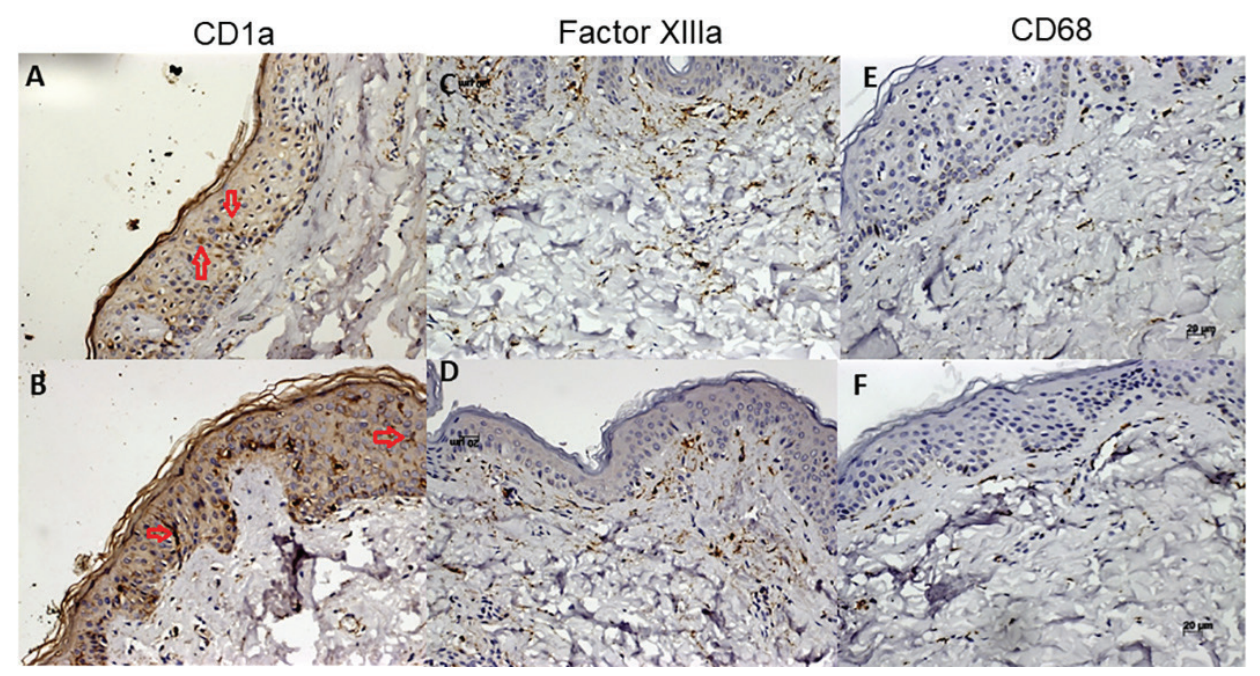

Figure 2 - Immunohistochemistry pattern of CD1a, Factor XIIIA and CD68. Cells density of CD1+ cells (red arrow) in lesion areas (A) and in a healthy control skin (B) Cell density of factor XIIla ${ }^{+}$cells in lesion areas (C) and in a healthy control skin (D) CD68+ cells in lesions areas skin (E) in a healthy control skin. Magnification: x 200. 


\section{DISCUSSION}

Dermatophytosis is a benign fungal infection that affects keratinized tissues, but, depending on the host immune status, it may progress to deep-seated infections, resulting in serious complications as severe forms include disseminated and/or invasive dermatophytosis, i.e., deep dermatophytosis and trichophytic granuloma (Majocchi's granuloma ${ }^{26,27}$. Due to the lack of studies exploring host-pathogen crosstalk in situ, immunopathological analyses may contribute to the understanding of the disease pathogenesis and the mechanisms associated to its different clinical presentations. In this study, we evaluated the histopathological changes in dermatophytosis lesions and the tissue distribution of DCs and macrophages, key cells in the host defense.

Our study showed a predominance of male patients $(70 \%)$ in agreement with previous studies ${ }^{1,28,29}$. The unequal incidence between both sexes can be explained by differences in occupational exposure ${ }^{28}$. Even though all ages are susceptible to chronic dermatophytosis, most of our patients $(70 \%)$ are between $30-50$ years old, an age interval coincident to individuals in the labor phase ${ }^{28}$.

Considering the essential role of APCs in determining the course of some infectious diseases, we evaluated these populations in our skin samples and detected a lower density of CD1a+ cells in dermatophytosis patients, raising the possibility that $T$. rubrum infection would be responsible for the decreased expression of this marker. We can postulate two potential, non-mutually exclusive, mechanisms for this observed decreased expression of CD1a: (i) downregulation of CD1a expression or (ii) decrease in the residing population of skin APCs due to their migration to regional lymph nodes for antigen presentation. Regarding the first possibility, it has been described that $T$. rubrum releases a variety of molecules, including protease ${ }^{30-32}$, that can interact with host cells and eventually lead to down regulation of the expression of surface markers such as CD1a in LCs, thereby interfering with their function. In our second hypothesis, activated skin APCs migrate to regional lymph nodes to induce adaptive immune responses, but the systemic cellular immune response of dermatophytosis patients shows a tendency towards a non-protective, pathology-inducing, Th-2 $2^{13,33,34}$ response, even though their LCs are able to produce pro-inflammatory mediators, IL-12 included, locally ${ }^{35}$. Thus, we hypothesize that $T$. rubrum (or its products)-mediated activation and migration of LCs from the epidermis would not necessarily result in better in situ protective responses.

Curiously, we have also observed a reduced expression of CD1a in the healthy/unaffected skin of dermatophytosis patients. Some authors showed a strong expression of CD1 proteins $(\mathrm{CD} 1 \mathrm{a},-\mathrm{b}$ and $-\mathrm{c})$ in patients with tuberculoid (benign) form of leprosy, while poor CD1a expression would be linked to the failure in pathogen restriction, characteristic of the lepromatous pole ${ }^{36}$. In cutaneous leishmaniasis, Jabbour et al. (2015) have also observed a decrease in CD1a expression and they postulated this could occur through two non-excluding mechanisms: either via direct CD1 a receptor uptake by Leishmania amastigotes or through a negative feedback inhibition of CD1a by double negative CD3 T-regulatory cells ${ }^{15}$. It is tempting to speculate that a decreased number of LCs may be a risk factor for the development of dermatophytosis and future studies should consider analyses of the healthy skin in dermatophytosis patients.

For DDs and macrophages, no association between cellular density and dermatophytosis status was found. Sotto et al. ${ }^{18}$ showed increased numbers of factor XIIIa+ cells in patients with American cutaneous leishmaniasis. DDs can internalize Leishmania amastigotes, thus participating in the pathogenic mechanisms by acting as APCs. T. rubrum, however, rarely reach the dermis and in none of our cases we could find hyphae or arthroconidia in this layer even by using a specific mycological staining (Grocott stain) (data not shown). Therefore, we speculate that the lack of alterations in the frequency of these two cell types could be explained by the lack of infection-driven inflammation in this compartment.

Albeit the inherent limitations of the IHC technique, and the restricted number of patients and surface markers employed, in summary, we showed here that $T$. rubrum infection is predominantly localized in the epidermis, where decreased numbers of LCs would result in defective antigen presentation; pointing to a possible mechanism for the chronicity or recurrence of this mycosis. Further studies should consider whether antifungal treatment would alter these observed abnormalities and if they are associated with active disease only.

\section{AUTHORS' CONTRIBUTIONS}

Reis APC; Correia FF and Jesus TM: generated the experimental data. Pagliari C: helped in the design of the study and in the IHC staining. Criado PR: inclusion of the patients and drafted the manuscript. Sakai-Valente NY: carried out the histologic diagnosis. Belda Júnior W: inclusion of the patients. Benard G: helped in the design of the study and drafted the manuscript. Sousa MGT: designed the study, analyzed the data and drafted the manuscript. All authors read and approved the final version of the manuscript. 


\section{CONFLICT OF INTERESTS}

The authors declare no conflict of interests.

\section{FINANCIAL SUPPORT}

This work was supported by Fundação de Amparo à Pesquisa do Estado de São Paulo (contracts N 2016/16369$1,2017 / 26208-8$ and 2018/24175-8). GB is a senior researcher of the Conselho Nacional para o Desenvolvimento Científico e Tecnológico.

\section{REFERENCES}

1. Seebacher C, Bouchara JP, Mignon B. Updates on the epidemiology of dermatophyte infections. Mycopathologia. 2008;166:335-52.

2. Jones HE, Reinhardt JH, Rinaldi MG. A clinical, mycological, and immunological survey for dermatophytosis. Arch Dermatol. 1973;108:61-5.

3. Kaviarasan PK, Jaisankar TJ, Thappa DM, Sujatha S. Clinical variations in dermatophytosis in HIV infected patients. Indian J Dermatol Venereol Leprol. 2002;68:213-6.

4. Weitzman I, Summerbell RC. The dermatophytes. Clin Microbiol Rev. 1995;8:240-59.

5. Sousa MG, Santana GB, Criado PR, Benard G. Chronic widespread dermatophytosis due to Trichophyton rubrum: a syndrome associated with a Trichophyton-specific functional defect of phagocytes. Front Microbiol. 2015;6:801.

6. Lanternier F, Pathan S, Vincent QB, Liu L, Cypowyj S, Prando C, et al. Deep dermatophytosis and inherited CARD9 deficiency. New Engl J Med. 2013;369:1704-14.

7. Martínez-Herrera EO, Arroyo-Camarena S, Tejada-García DL, Porras-López CF, Arenas R. Onychomycosis due to opportunistic molds. An Bras Dermatol. 2015;90:334-7.

8. Lanternier F, Mahdaviani SA, Barbati E, Chaussade H, Koumar Y, Levy R, et al. Inherited CARD9 deficiency in otherwise healthy children and adults with Candida species-induced meningoencephalitis, colitis, or both. J Allergy Clin Immunol. 2015;135:1558-68.

9. Marconi VC, Kradin R, Marty FM, Hospenthal DR, Kotton CN. Disseminated dermatophytosis in a patient with hereditary hemochromatosis and hepatic cirrhosis: case report and review of the literature. Med Mycol. 2010;48:518-27.

10. Blanco JL, Garcia ME. Immune response to fungal infections. Vet Immunol Immunopathol. 2008;125:47-70.

11. Grumach AS, Queiroz-Telles F, Migaud M, Lanternier F, Filho NR, Palma SM, et al. A homozygous CARD9 mutation in a Brazilian patient with deep dermatophytosis. J Clin Immunol. 2015;35:486-90

12. Burstein VL, Guasconi L, Beccacece I, Theumer MG, Mena C,
Prinz I, et al. IL-17-mediated immunity controls skin infection and $\mathrm{T}$ helper 1 response during experimental Microsporum canis dermatophytosis. J Invest Dermatol. 2018;138:1744-53.

13. Heinen MP, Cambier L, Antoine N, Gabriel A, Gillet L, Bureau

$\mathrm{F}$, et al. Th1 and Th17 immune responses act complementarily to optimally control superficial dermatophytosis. J Invest Dermatol. 2019;139:626-37.

14. Chai LY, Netea MG, Vonk AG, Kullberg BJ. Fungal strategies for overcoming host innate immune response. Med Mycol. 2009;47:227-36.

15. Jabbour MN, Issa G, Charafeddine K, Simaan Y, Karam M, $\mathrm{Khalifeh} \mathrm{H}$, et al. The immune microenvironment in cutaneous leishmaniasis. J Eur Acad Dermatol Venereol. 2015;29:1170-9.

16. Criado PR, Oliveira CB, Dantas KC, Takiguti FA, Benini LV, Vasconcellos C. Superficial mycosis and the immune response elements. An Bras Dermatol. 2011;86:726-31.

17. Asahina A, Tamaki K. Role of Langerhans cells in cutaneous protective immunity: is the reappraisal necessary? J Dermatol Sci. 2006;44:1-9.

18. Sotto MN, Halpern I, Kauffman MR, Pagliari C. Factor XIIIa+ dermal dendrocyte parasitism in American tegumentary leishmaniasis skin lesions. Am J Dermatopathol. 2010;32:15-8.

19. Silva WL, Pagliari C, Duarte MI, Sotto MN. Paracoccidioides brasiliensis interacts with dermal dendritic cells and keratinocytes in human skin and oral mucosa lesions. Med Mycol. 2016;54:370-6.

20. Braathen LR, Kaaman T. Human epidermal Langerhans cells induce cellular immune response to trichophytin in dermatophytosis. Br J Dermatol. 1983;109:295-300.

21. Pakula AS, Paller AS. Langerhans cell histiocytosis and dermatophytosis. J Am Acad Dermatol. 1993;29:340-3.

22. Hsu SM, Raine L, Fanger H. Use of avidin-biotin-peroxidase complex $(\mathrm{ABC})$ in immunoperoxidase techniques: a comparison between $\mathrm{ABC}$ and unlabeled antibody (PAP) procedures. J Histochem Cytochem. 1981;29:577-80.

23. Park YW, Kim DY, Yoon SY, Park GY, Park HS, Yoon HS, et al. 'Clues' for the histological diagnosis of tinea: how reliable are they? Ann Dermatol. 2014;26:286-8.

24. Matejuk A. Skin immunity. Arch Immunol Ther Exp (Warsz). 2018;66:45-54.

25. Pagliari C, Sotto MN. Correlation of factor XIIIa+ dermal dendrocytes with paracoccidioidomycosis skin lesions. Med Mycol. 2002;40:407-10.

26. Alves de Medeiros AK, Lodewick E, Bogaert DJ, Haerynck F, Van Daele S, Lambrecht B, et al. Chronic and invasive fungal infections in a family with CARD9 deficiency. J Clin Immunol. 2016;36:204-9.

27. Drewniak A, Gazendam RP, Tool AT, van Houdt M, Jansen MH, van Hamme JL, et al. Invasive fungal infection and impaired neutrophil killing in human CARD9 deficiency. Blood. 2013;121:2385-92. 
28. Bhatia VK, Sharma PC. Epidemiological studies on Dermatophytosis in human patients in Himachal Pradesh, India. Springerplus. 2014;3:134.

29. Teklebirhan G, Bitew A. Prevalence of dermatophytic infection and the spectrum of dermatophytes in patients attending a tertiary hospital in Addis Ababa, Ethiopia. Int J Microbiol. 2015;2015:653419.

30. Lambkin I, Hamilton AJ, Hay RJ. Partial purification and characterization of a $235,000 \mathrm{M}(\mathrm{r})$ extracellular proteinase from Trichophyton rubrum. Mycoses. 1994;37:85-92.

31. Brasch J, Martins BS, Christophers E. Enzyme release by Trichophyton rubrum depends on nutritional conditions. Mycoses. 1991;34:365-8.

32. Martinez-Rossi NM, Peres NT, Rossi A. Pathogenesis of dermatophytosis: sensing the host tissue. Mycopathologia. 2017;182:215-27.
33. Heinen MP, Cambier L, Fievez L, Mignon B. Are Th17 cells playing a role in immunity to dermatophytosis? Mycopathologia. 2017;182:251-61.

34. Leibovici V, Evron R, Axelrod O, Westerman M, Shalit M, Barak V, et al. Imbalance of immune responses in patients with chronic and widespread fungal skin infection. Clin Exp Dermatol. 1995;20:390-4.

35. Kang K, Kubin M, Cooper KD, Lessin SR, Trinchieri G, Rook AH. IL-12 synthesis by human Langerhans cells. J Immunol. 1996;156:1402-7.

36. Sieling PA, Jullien D, Dahlem M, Tedder TF, Rea TH, Modlin RL, et al. CD1 expression by dendritic cells in human leprosy lesions: correlation with effective host immunity. J Immunol. 1999;162:1851-8. 